\title{
Distribution Models for Logistics in HORECA Channel
}

\author{
Eva Ponce-Cueto, Ruth Carrasco-Gallego \\ Industrial Engineering and Business Administration Department \\ Escuela Técnica Superior de Ingenieros Industriales, Universidad Politécnica de Madrid (UPM), Spain \\ eva.ponce@upm.es, ruth.carrasco@upm.es
}

\begin{abstract}
The main aim of this paper is to identify and describe the operational models that are currently being used in Spain for physical distribution for the HORECA channel and to propose a selection guide that will allow the manufacturer to select the distribution model that best fits their system according to a set of operational variables. Firstly, a description of the present situation of the HORECA channel in Spain will be given. Secondly, we will outline the complete cycle order-delivery-payment in each one of the distribution models identified for this channel: auto-sales, pre-sales, direct delivery, distributor (manufacturer sales), and distributor (distributor sales). Thirdly, operational variables are defined that help the manufacturer identify which distribution model is more appropriate according to their needs and a selection guide is proposed (main contribution of this study). Finally, the conclusions of the study are presented and future developments in this area are outlined.
\end{abstract}

Keywords: logistics systems, distribution, HORECA channel.

\section{INTRODUCTION}

The term HORECA refers to the distribution channel in the food service industry. It is the acronym formed by linking the words HOtel, REstaurant and CAtering.

The HORECA channel in Spain is very fragmented, with more than 330,000 total points of sales (Accenture-AECOC, 2004). Likewise, a tendency toward professionalization and concentration of the sector through organized chains has also been seen.

The majority of manufacturers distinguish between the "organized" HORECA channel and the "non-organized" channel. The first is the one established, for example, with some hotel chains (NH Hoteles, Sol Meliá, Paradores, Riu Hoteles, etc.), restaurant chains (Burger King, McDonalds, Telepizza, VIPS group, Corte Inglés-Restauración, etc.) and with the restaurant industry that supplies, for example, the hospital market, penitentiaries, schools, work canteens, airline catering, etc. The second type, the "non-organized" HORECA channel, is the one that supplies small bars and restaurants, some hotels, etc. A series of problems associated with the distribution channel have been identified in both cases.

For some manufacturers the HORECA channel represents around $30 \%$ of their total distribution, while for others it is less than $10 \%$. The manufacturers interviewed in this study coincide in that one of the main problems in this sector is the high logistics costs (a consequence of the size of orders, generally very small, and of the deliveries, which are very frequent).

For the physical distribution of their products, manufacturers can opt to (a) deliver directly to the client themselves, (b) use distributors that are responsible for the deliveries in a certain geographical zone, (c) sub-contract distribution to a logistics operator or (d) a mixed model depending on the type of product and destination. There are also specialized logistics services on the market in the HORECA channel, targeted at reducing the high logistics costs associated with this sector. (e.g. LogiRest)

\section{OBJECTIVES AND METHODOLOGY}

The manufacturers dealing with HORECA customers have identified two structural problems in this channel which will constitute the starting point of this study. On the one hand, there is the impossibility of offering a homogeneous level of services throughout the country. This problem is especially relevant in the case of customers belonging to the "organized" HORECA, since hotel chains, restaurant chains, etc. usually require a certain level of service in contracts, which the manufacturer should be able to provide in a homogeneous manner in the entire country. Nevertheless, the elevated requirements from a logistics point of view of this type of distribution (urban last-mile, many small deliveries, perishable products, frequent problems in the billing process...) and the great volume of resources that are involved, mean that few manufacturers can offer a uniform level of services in all geographical zones, independently of whether physical distribution is incorporated into their internal processes or if it is outsourced through Third Part Logistics (3PLs) operators. To this effect, the manufacturers participating in this study have underscored the difficulty of finding a single logistic operator who can provide an adequate level of service in all the needed areas. The 3PLs have different capacities and availability of resources according to the geographical area in question, which forces manufacturers who supply the HORECA channel to 
establish agreements with different subcontractors (3PLs, distributors) to guarantee the homogeneous level of services in the entire country required by their customers.

On the other hand, the other structural problem identified in this type of distribution is the elevated costs associated with the order-delivery-payment cycle. It is estimated that these costs in the HORECA channel are four times greater than in large-scale retail (Accenture- AECOC, 2004). These high costs in comparison with other logistics systems are due to multiple factors (very small orders, very frequent deliveries...).

Finally, we should point out that researching this topic is of interest. A review of the existing literature has made it evident that there is scarcely any scientific literature written specifically on logistics processes in the HORECA channel.

\subsection{Objectives}

The main aim of this paper is to identify and describe the operational models that are currently being used in Spain for physical distribution for the HORECA channel and to propose a selection guide that will allow the manufacturer to select the distribution model that best fits their system according to a set of operational variables, which will also be defined in this study.

\subsection{Methodology}

The methodology followed to reach these objectives consisted of two main stages:

- Literature review. Scientific journals, magazines, company studies, etc. were reviewed. As a result of this stage, it became clear that there are very few studies centered on the problems associated with the HORECA distribution channel.

- $\quad$ Meetings of experts (task groups). The working group "The future of the HORECA channel in Spain” was formed, organized by the Logistics Spanish Center (CEL) and sponsored by IBM Global Business Services. The authors of this article participated in this group. The study is approached from the point of view of the manufacturers, who were the main participants in the group and who have contributed their complete view of the problems related with this distribution channel. The meetings took place each six weeks. A project plan was sent to each group member before each meeting. Group members carried out their tasks and presented the results of these at the meeting, discussing them jointly with the other members. Minutes were taken at each meeting and sent to all the participants along with the other documentation seen during the meeting.
In the following paragraphs the results stemming from the study will be presented and a selection guide proposed that will allow manufacturers to choose the distribution model most adequate for their system.

\section{DISTRIBUTION MODELS FOR HORECA CHANNEL}

In this section, the five distribution models for the HORECA channel identified in this study will be briefly described. Both the information flow (continuous black line) as well as the financial flow (dotted green line) and physical flow of goods (dotted blue line) associated with the order-delivery-payment cycle have been represented for each of them.

\subsection{Pre-Sales Model}

The main characteristic of the pre-sales model (Figure 1) is that orders are placed before delivery, usually the day before $(\mathrm{J}-1)$. The order is placed either by a sales agent who carries out a predefined sequence of visits to customers (this sequence will become the distribution route the following day), or by the delivery truck driver, whose job is two-fold, both sales and logistics, providing service to the set of customers that are assigned to him and that are usually located in the same geographical zone constituting a delivery route. In any case, with the orders received in $\mathrm{J}-1$, the manufacturer puts sufficient inventory to supply day J orders at the disposal of the delivery routes. Delivery may be done by the manufacturers themselves through their own means, available at different national offices, or outsourced to a logistics operator.

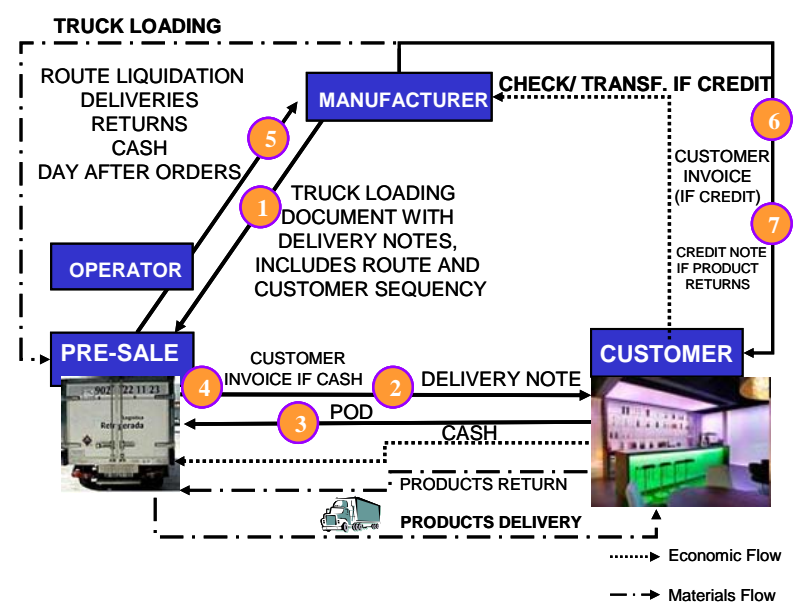

Figure 1. Pre-Sales Model. Sources: IBM Global Business Services (2006).

Another important characteristic in both the pre-sales and auto-sales (model 3.2.) models is the possibility of the customer paying in cash at the time of delivery. This is one of the historical peculiarities of the HORECA channel that continues to exist in this sector, not very accustomed to billing later, which means giving customers a certain credit limit. 


\subsection{Auto-Sales Model}

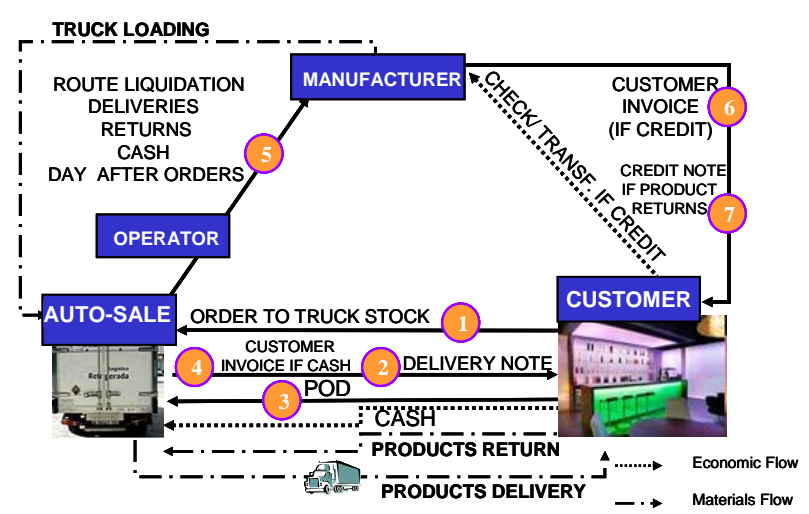

Figure 2. Auto-Sales Model. Sources: IBM Global Business Services (2006).

The principal difference between this model and the pre-sales model (Figure 2) is that in this case placing an order prior to delivery is not necessary for delivery to be made. The delivery vehicle is loaded to maximum capacity before departure with a selection of the manufacturer's products and with a predetermined quantity of each one. The driver follows the route of customers which has been assigned without prior knowledge as to the quantities that will be delivered to each of the customers. It is completely possible that no order will materialize. If the customer called on is interested in receiving supplies, the order, delivery and, usually, the payment take place simultaneously. If the stock available in the vehicle were not sufficient to cover the necessities of the day of the customers on the route, a series of orders would be left pending to be supplied the next day.

Certain interesting analogies can be drawn between this model and the rolling warehouse model used for lastmile distribution by some e-commerce companies described in Lee and Whang (2001). The main disadvantage of this model in comparison with the one outlined in section 3.1 is that a high percentage of business calls do not produce deliveries. This means empty trips for the delivery truck, generally merchandise distribution in an urban context. This causes logistics costs to be higher than they should be since they include a part of the costs arising from sales efforts. Although the auto-sales model has been the traditional sales and delivery format in the HORECA channel, there are several factors such us, the pressure to optimize logistics costs, price increases in last-mile distribution, and increasingly strict local ordinances, especially in historic city centers, that augment the probability that this model will have to evolve toward other working formats in the future.

In the auto-sales model, a series of previously assigned customers are serviced by the vehicle. In both models, it is important to periodically review assigned customer routes in order to balance work loads and to avoid having vehicles with a great quantity of surplus stock or with many orders pending for the following day in the case of auto-sales.

The principal advantages of the pre-sales model over the auto-sales model are the following: better route planning, promoting sales and reducing stockouts.

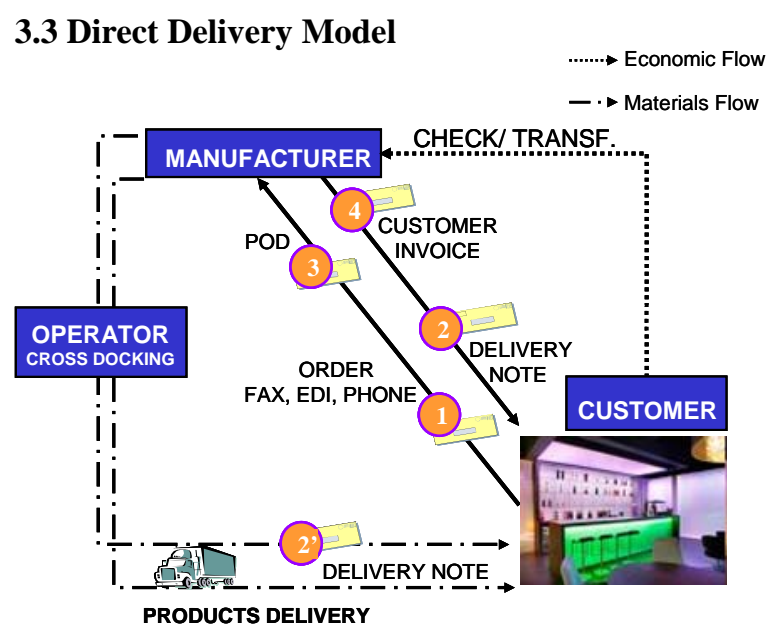

Figure 3. Direct Delivery Model. Sources: IBM Global Business Services (2006).

In this model (Figure 3), the initiative originates with the customer, who sends the order directly to the manufacturer via telematic means, including telephone, fax, e-mail, EDI or order extranets. Although delivery may be outsourced to a logistics operator, in any case the delivery note and the acknowledgement of receipt acts as a proof that the delivery has been made and starts the invoicing process, which is carried out directly, without middlemen, between the manufacturer and the HORECA customer. This is the most frequently used model in the organized HORECA channel.

\subsection{Distributor Model: manufacturer sales}

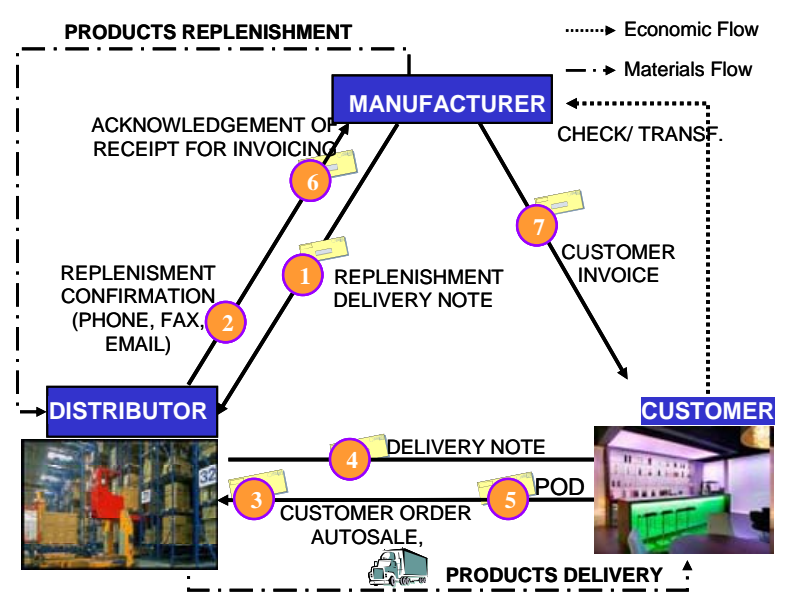

Figure 4. Distributor Model: manufacturer sales. Sources: IBM Global Business Services (2006).

Another option for manufacturers to reach the distribution level demanded in such a fragmented and geographically dispersed channel such as HORECA, is 
to rely on small local distributors to support their delivery processes. In this section, we will present the model which corresponds to the supply of customers who establish their business relationship directly with the manufacturer, even though logistically they are supplied by a distributor who acts in the name of the manufacturer (Figure 4). This model differs from that discussed in section 3.5 (distributor sales), in that the customer does not establish the business relationship with the manufacturer, but directly with the distributor. Generally, the model shown in figure 4 is thought to be more advantageous for the manufacturer since it provides greater visibility and influence over the channel. In the case of distributor sales, the manufacturer loses control over the end customer.

\subsection{Distributor Model: direct sales}

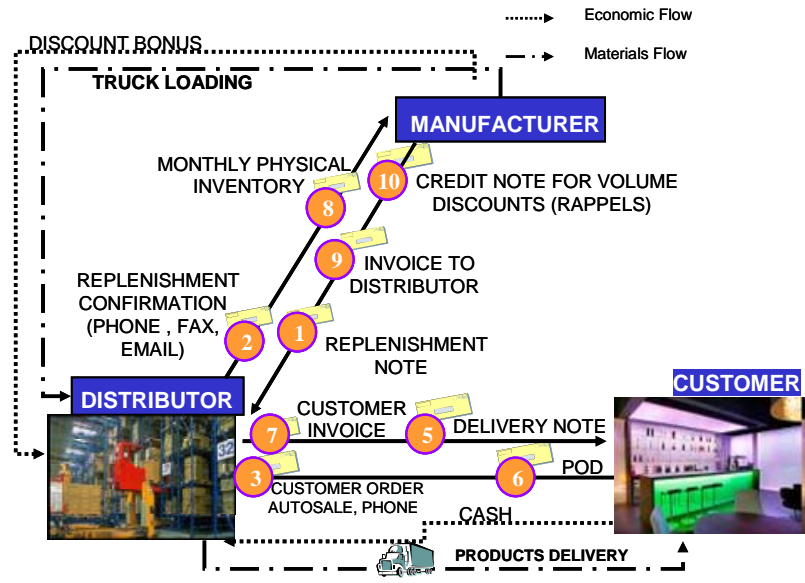

Figure 5. Distributor Model: distributor sales. Sources: IBM Global Business Services (2006).

In this model (Figure 5), the HORECA customer establishes the business relationship directly with the distributor. The manufacturer does not participate at any time in the billing and payment processes with the customer. Regarding delivery, the distributor can opt to deliver the product to the HORECA customer or have the customers come directly to the distributor to receive supplies. This second option would be the cash \& carry distribution model.

As far as billing and payment between the manufacturer and distributor are concerned, it is common practice to carry out a monthly inventory of the distributor's warehouse. It is understood that the difference between the total volume supplied by the manufacturer and the volume consumed in deliveries to customers of the manufacturer (model outlined in section 3.4) corresponds to the sales made by the distributor to their own customers. According to the results of the inventory, the manufacturer sends a monthly bill to the supplier for goods. In both the model described in section 3.4 as well as the one in section 3.5, the fact that a distributor has to be relied on to deliver the products supposes a series of drawbacks such as:
- The distributor shares the manufacturer's brand with other brands.

- The distributor is concentrated on his business and the strategy that he employs may not always be in accordance with that of the manufacturer who contracts their services.

- The fact that another actor intervenes in the supply chain reduces the visibility of the process for the manufacturer (the manufacturers' experience is that the number of incidents involving the end customer and the manufacturer increases and the lack of information about the incident makes its solution more difficult).

\section{OPERATIONAL VARIABLES AND SELECTION GUIDE OF DISTRIBUTION MODEL}

Once the models were identified and outlined, we then determined a set of operational variables that would aid in choosing the most adequate distribution model for a HORECA channel customer or group of customers depending on the values of these variables.

In the first stage of the study, the experts identified a total of 20 possible operational variables using the brainstorming technique. In the second stage, in an attempt to maintain only those variables that are truly important in choosing a particular distribution model, a set of five operational variables were chosen applying the criteria of redundancy and relevance. The operational variables finally selected (by the experts) as important in determining the appropriate distribution model were the following: order and supply frequency; order size; product shelf life (sell-by date); defined service quality; delivery requirements: location, schedule, maintenance necessities, etc.

Each of these variables will be defined and described briefly in the following paragraphs.

\subsection{Order Frequency}

The frequency of order and supply is defined as the average period of time that elapses between the orders of a particular customer. As shown in table 1, the order frequency is predetermined in the pre-sales and auto-sales models, while in the rest of the models it is the customer who takes the initiative in placing the order. In the pre-sales model, the order frequency is elevated, generally daily. In the auto-sales model, the order frequency is usually weekly or biweekly. In the rest of the models, given that product volume is characteristically greater (approximately a pallet), the placement of an order occurs according to the needs of the customer and frequency can vary between daily orders to weekly or monthly orders. Some factors that may influence the frequency with which customers place orders are the HORECA customer's storage facility capacity or obsolescence (sell-by dates, perishability, durability) of the product concerned. 


\subsection{Order Size}

Order size is one of the variables that most clearly determines the distribution model chosen. The pre-sales and auto-sales models constitute the classic distribution model for supplying small product quantities. As order size increases, there is a tendency toward supplying through direct delivery models. The model of sales through the distributor (either with manufacturer or distributor sales) emerges when customers have a considerable geographic dispersion and order volume is not sufficiently large to warrant logistics costs, from the manufacturer's point of view.

The main difficulty that arises with the "order size" variable is that it is impossible to establish generically (valid for all types of products) what is considered a "large" order and what is understood as a "small order". The same volume of merchandise may be considered a large order for cereal manufacturers while for drink manufacturers that same volume would be a small order. For this reason, it was decided to define the "order size" variable as a percentage of the merchandise contained on a pallet that is delivered in an average order. The percentages indicated in table 1 (line 2) are merely indicative, since each manufacturer would have to adapt the percentages to their particular situation. The working group decided that an order less than the size of a pallet is "small" and those larger than a pallet are "large".

\subsection{Deadline for Deliveries (product shelf life, sell-by date)}

This variable is defined as the difference between the preferred consumption date or sell-by date and the date of reception of merchandise in the distributor's or customer's inventory. This represents the remaining product shelf life when the product has been received by the customer or HORECA distributor. Although Spanish legislation does not yet require it, manufacturers and customers may reach an agreement that guarantees the HORECA customer a minimum shelf life in perishable products. This type of agreement usually favors the use of models that avoid the existence of intermediary distributors (pre-sales, auto-sales or direct delivery), since the existence of an intermediary inevitably slows the rotation of products throughout the supply chain.

As can be seen in line 3 of Table 1, no value for the "deadline for deliveries" variable has been included in those models which include the intervention of a distributor, given that in these cases the manufacturer cannot control the date of receipt by the customer. It is important to remember that the study was carried out from the point of view of the manufacturer.

\subsection{Service Quality}

Within the working group, the service quality variable was defined from a dual point of view. On the one hand, this variable measures the degree of fulfillment of the level of service agreed to with each HORECA customer using the percentage of references/lines of orders delivered on time. On the other hand, the experts in the group pointed out the importance of this variable reflecting not only the service quality offered to the customer, but also if this service quality is directly controllable by the manufacturer.

In the models where a distributor agent intervenes, although reaching a high degree of service quality, it cannot be directly controlled by the manufacturer. Generally, for HORECA customers who demand a high degree of service quality, manufacturers usually opt for the pre-sales or direct delivery models. Since there is no prior order (the order and the delivery are simultaneous) with the auto-sales model, it makes no sense to use the service quality parameter in the same terms as defined here.

\subsection{Delivery Requirements}

Just as with service quality, the manufacturer and HORECA customer may agree to a set of requirements or restrictions that should be fulfilled at the time of delivery, such as set receiving times, unloading by the manufacturer (need for maintenance) or refrigeration. Similarly to the situation with service quality, the manufacturer can only assure fulfillment of these delivery requirements in the models in which he has direct control over delivery, thus excluding the models that need an intermediary distributor.

Therefore, as indicated in table 1, the existence of a set of delivery requirements previously agreed upon with the customer generally favors the use of the pre-sales and direct delivery models.

\subsection{Decision Matrix}

Table 1 below summarizes the aspects that have just been analyzed. It is meant to serve as a selection guide for those manufacturers who operate in the HORECA channel and who must select the most adequate distribution model for their system. The operational variables defined in the study and the assessment of each of them for the five distribution models identified in the study for the HORECA channel have been included. Thusly, manufacturers can choose which of the five models best suits their needs.

\begin{tabular}{|c|c|c|c|c|c|}
\hline & PRE-SALES & AUTO-SALES & $\begin{array}{c}\text { DIRECT } \\
\text { DELIVERY }\end{array}$ & $\begin{array}{l}\text { DISTRIB. } \\
\text { (MANUF.) }\end{array}$ & $\begin{array}{l}\text { DISTRIB. } \\
\text { DIRECT } \\
\text { SALES }\end{array}$ \\
\hline Order frequency & Daily & $\begin{array}{l}\text { Weekly / } \\
\text { Biweekly }\end{array}$ & $\begin{array}{l}\text { According } \\
\text { to customer } \\
\text { needs }\end{array}$ & As needed & As needed \\
\hline Order size (\% pallet) & $<10 \%$ & $10-25 \%$ & 2-10 pallet & 5-33 pallet & 5-20 pallet \\
\hline $\begin{array}{l}\text { Deadline for deliveries } \\
\text { (\% product shelf life) }\end{array}$ & $85 \%$ & $85 \%$ & $100 \%$ & & \\
\hline Service Quality & Yes & No & Yes & No & No \\
\hline Delivery Requirements & Yes & No & Yes & No & No \\
\hline
\end{tabular}

Table 1. Decision Matrix. A Selection Guide for choosing the appropriate distribution model. 


\section{CONCLUSIONS AND FURTHER DEVELOPMENTS}

The analysis of the selected operational variables leads us to conclude that the pre-sales and auto-sales distribution models are the most adequate for frequent and small orders, whereas direct delivery usually implies larger volume orders. Manufacturer sales through a distributor are the most appropriate when the manufacturer has difficulties in reaching the end customer, whether this is due to low frequency of orders or because of the high logistics costs involved in reaching the customer. If the manufacturer wishes to directly control the level of the logistics services offered to the customer and the fulfillment of delivery requirements imposed by the customer (schedule, accessibility, maintenance, etc.), it is necessary to turn to the pre-sales and direct delivery models. The distributor sales model implies a high hidden cost: loss of visibility and the manufacturer's loss of control over the HORECA market. The high logistics costs in this channel cause many manufacturers to contract logistics operators or to use distributors for the physical distribution of their products. The latter can attain economies of scale, by, for example, grouping orders.

Now that the processes that take place in the order-delivery-payment cycle of each model have been outlined and the corresponding stages have been broken down, as future research we propose identifying the critical points and inefficiencies in each one of the three aspects (order capture, delivery execution, billing and payment) and proposing solutions that would better the efficiency of these processes.

\section{ACKNOWLEDGEMENTS}

We would like to thank all of the HORECA task group participants for their contributions and, especially, the contribution of Ramón García, leader of innovative projects in the Spanish Logistics Center (CEL).

\section{REFERENCES}

[1] Accenture-AECOC. Report "Retos y oportunidades de la cadena de suministro del Canal HORECA". October, 2004.

[2] Cooper, M., Douglas, L., J.D. Pagh, "Supply Chain Management: More than a New Name for Logistics”, The International Journal of Logistics Management, Vol. 8, No. 1, pp. 1-14, 1997.

[3] IBM Global Business Services. "Modelos de distribución en el canal HORECA”. Presentación Grupo de Trabajo CEL-El futuro del Canal HORECA en España. November 2006.

[4] Lee, H.L., S. Whang, "Winning the last mile of e-commerce”. MIT Sloan Management Review, Vol. 42, No. 4, pp. 54-62, 2001.

[5] LogiRest (Logistics services for HORECA channel) URL (Consulted in March 2008): http://www.logista.es/LogistaWeb_v2/interior1.asp?I D_Pagina $=154$ 